\title{
Catalytic Plasma Reactor for Abatement of Dilute Nitrobenzene
}

\author{
J. KARUPPIAH ${ }^{1}$, L. SIVACHRANDIRAN ${ }^{2}$, R. KARVEMBU ${ }^{1}$, Ch. SUBRAHMANYAM ${ }^{2, *}$ \\ ${ }^{1}$ Department of Chemistry, National Institute of Technology, Tiruchirappalli 620015, India \\ ${ }^{2}$ Department of Chemistry, Indian Institute of Technology Hyderabad, Yeddumailaram 502205, India
}

\begin{abstract}
Oxidative decomposition of dilute nitrobenzene in air was carried out in a catalytic plasma reactor with an inner electrode made of sintered metal fibres (SMF) that also acted as catalyst. The parameters of the concentration, specific input energy, and gas residence time were optimized. The modification of the SMF inner electrode with transition metal oxides like $\mathrm{MnO}_{x}$ and $\mathrm{CoO} x$ oxides promoted complete oxidation, especially at low input energy. $\mathrm{CoO}_{x} / \mathrm{SMF}$ showed higher activity than $\mathrm{MnO}_{x} / \mathrm{SMF}$ and SMF, and could oxidise completely 100 ppm of nitrobenzene at $300 \mathrm{~J} / \mathrm{L}$.
\end{abstract}

Key words: volatile organic compound abatement, nonthermal plasma, dielectric barrier discharge, nitrobenzene, sintered metal fibre CLC number: O643 Document code: A

Received 1 November 2010. Accepted 8 December 2010.

*Corresponding author. Fax: +91-40-23016032; E-mail: csubbu@iith.ac.in

English edition available online at Elsevier ScienceDirect (http://www.sciencedirect.com/science/journal/18722067).

Volatile organic compounds (VOCs) are the primary toxic pollutant emitted from chemical industrial and automobile exhausts. Some VOCs are carcinogens and harmful to living organisms [1,2]. Nitrobenzene is widely used in many industrial processes as raw material or solvent and in the manufacture of lubricant oils and dyes. In addition, pesticides and drugs also contain large amounts of nitrobenzene. Excessive exposure to nitrobenzene may affect the reproductive system and also may cause skin cancer [3]. To limit the adverse health effect of nitrobenzene, many countries have emission regulations for it. Many techniques including the use of a nonthermal plasma (NTP) have been tested for the abatement of nitrobenzene. However, many of the techniques are not useful for the removal of nitrobenzene present at low concentrations. Conventional techniques for VOC abatement are thermal oxidation, catalytic oxidation, and carbon adsorption [4,5]. The thermal oxidation and catalytic oxidation methods have the drawback of high operating temperatures. Carbon adsorption is relatively simple but needs a secondary treatment for the removal of adsorbed contaminants. Since the conventional methods are effective only when the VOC concentration is higher than 1000 ppm, there is a need to develop an alternate, efficient, and low energy process. In this regard, the NTP has unique advantages, like ease of operation and presence of highly energetic electrons, over the conventional methods for the removal of VOCs in the gas phase. NTP can generate highly energetic electrons and operate at atmospheric pressure with the background gas at ambient conditions [6-9]. Moreover, when operated in air, NTP produces potentially active spe- cies like $\mathrm{N}_{2} *\left(\mathrm{~A}^{3} \Sigma_{\mathrm{u}}^{+}\right), \mathrm{N}_{2} *\left(\mathrm{~B}^{3} \Pi_{\mathrm{u}}^{+}\right), \mathrm{O}_{2} *\left(\mathrm{a}^{1} \Delta_{\mathrm{g}}\right), \mathrm{O}\left({ }^{1} \mathrm{D}\right), \mathrm{O}\left({ }^{3} \mathrm{P}\right)$, and $\mathrm{N}\left({ }^{4} \mathrm{~S}\right)$ in addition to ozone [9,10]. Dielectric barrier discharge (DBD), one of the NTP techniques, has the advantageous of a uniform distribution of the micro-discharges throughout the discharge. These micro-discharges initiate the chemical reaction by electron impact dissociation of organic molecules as well as ionization of the carrier gas.

The NTP technique has been employed successfully for the destruction of various VOCs like aromatics, aliphatic hydrocarbons [11-14], and inorganic pollutants such as $\mathrm{SO}_{2}$, $\mathrm{H}_{2} \mathrm{~S}$, and $\mathrm{NO}_{x}$ [15-17]. One of the limitations of the NTP technique is low selectivity towards total oxidation. To some extent, the selectivity can be improved by combining NTP with heterogeneous catalysts [18-20]. The action of the catalyst is to utilise the oxidants formed in the plasma to bring about a synergy between plasma and catalytic action $[21,22]$. In the present study, the design of a DBD reactor for the complete oxidation of nitrobenzene was studied with a modified inner electrode made of sintered metal fibres (SMF). The objective was to achieve the total oxidation of dilute nitrobenzene. Optimization of various parameters like catalyst, input energy, concentration of VOC, and formation of ozone on the performance of the plasma reactor was performed.

\section{Experimental}

Nitrobenzene was introduced into the reactor by a motor driven syringe pump. It was diluted with air. The gas flow 
rate was varied between 250 to $750 \mathrm{ml} / \mathrm{min}$ by a mass flow controller (MFC, Alborg). The input concentration of nitrobenzene was varied between 100 to 500 ppm by adjusting the gas flow rate. The reactor outlet was connected to a gas chromatograph (Varian 450) equipped with a FID detector and a GP capillary column (50 m length, $0.25 \mathrm{~mm}$ diameter, and $0.5 \mu \mathrm{m}$ film thickness) to measure the nitrobenzene conversion. The products $\left(\mathrm{CO}, \mathrm{CO}_{2}\right)$ formed during nitrobenzene oxidation was measured by an infrared analyzer. The selectivities for $\mathrm{CO}_{2}$ and $\mathrm{CO}_{x}$ used were

$$
\begin{aligned}
& S_{\mathrm{CO}_{2}}(\%)=\frac{\left[\mathrm{CO}_{2}\right]}{6\left([\mathrm{VOC}]_{\mathrm{IN}}-[\mathrm{VOC}]_{\mathrm{OUT}}\right)} \times 100 \\
& S_{\mathrm{CO}_{x}}(\%)=\frac{\left[\mathrm{CO}_{x}\right]}{6\left([\mathrm{VOC}]_{\mathrm{IN}}-[\mathrm{VOC}]_{\mathrm{OUT}}\right)} \times 100
\end{aligned}
$$

where $\left[\mathrm{CO}_{x}\right]$ and $\left[\mathrm{CO}_{2}\right]$ are the outlet concentrations of $\mathrm{CO}_{x}$ and $\mathrm{CO}_{2}$, respectively, and $[\mathrm{VOC}]_{\mathrm{IN}}$ and $[\mathrm{VOC}]_{\mathrm{OUT}}$ are the initial and final concentrations of nitrobenzene, respectively. Since partially oxidized products were not observed in the present work, the selectivity for $\mathrm{CO}_{x}$ also represented the mass balance. Ozone concentration in the plasma reactor was measured with an UV absorption ozone monitor (API-450 NEMA).

\subsection{Catalyst preparation}

SMF filters made of stainless steel with $0.29 \mathrm{~mm}$ thickness, $80 \%$ porosity, and $675 \mathrm{~g} / \mathrm{m}^{2}$ surface area were used as the inner electrodes. Their modified counterparts with a deposited catalyst $\left(\mathrm{MnO}_{x} / \mathrm{SMF}\right.$ and $\left.\mathrm{CoO}_{x} / \mathrm{SMF}\right)$ were also used. For the deposition of $5 \mathrm{wt} \% \mathrm{MnO}_{x}$ and $\mathrm{CoO}_{x}$, the SMF was first oxidised at $873 \mathrm{~K}$ for $3 \mathrm{~h}$, followed by impregnation with Co or Mn nitrate solution. Drying at room temperature and calcination at $773 \mathrm{~K}$ for $5 \mathrm{~h}$ gave a metal oxide catalytic film deposited on SMF. Finally, the SMFs were shaped into a cylindrical form with a diameter of 12.5 $\mathrm{mm}$.

\subsection{Plasma reactor and discharge characterization}

The details of the DBD reactor have been given elsewhere. It is shown in Fig. 1 [22]. The discharge was generated in a cylindrical glass tube with an inner diameter of $18.5 \mathrm{~mm}$ and a wall thickness of $1.5 \mathrm{~mm}$. Silver pasting on

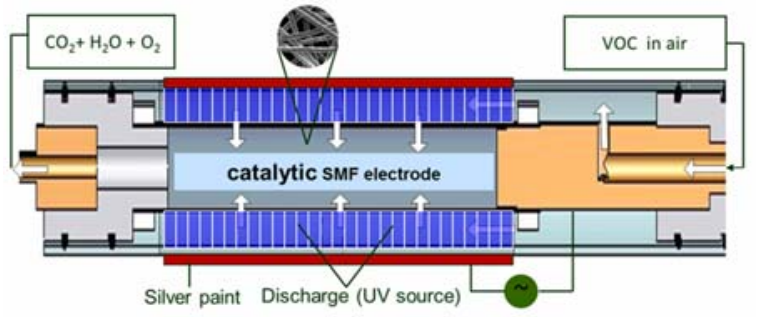

Fig. 1. Schematic of the DBD plasma reactor [22].

the outer surface of the glass tube acted as the outer electrode. The modified SMF cylinder was the inner electrode. The discharge length was $10 \mathrm{~cm}$ and discharge gap was fixed at $2.5 \mathrm{~mm}$. One end of the SMF electrode was connected by a stainless steel rod to an alterhating current (AC) high voltage source. The other end was connected by a teflon tube to the gas chromatograph. The discharge was generated by applying an $\mathrm{AC}$ high voltage in the range of 14-22.0 kV (peak to peak), which was generated by a high voltage source (Jayanthi Transformer) at $50 \mathrm{~Hz}$. The reacting gas passing through the discharge zone diffused through the SMF electrode. The conversion of nitrobenzene was recorded after $30 \mathrm{~min}$.

The electrical circuit is shown in Fig. 2. The voltage-charge (V-Q) Liassajous method was used to determine the discharge power generated in the reactor. Figure 3 shows a typical V-Q Lissajous figure for $22 \mathrm{kV}$ at a frequency of $50 \mathrm{~Hz}$. The area of the V-Q figure is the energy dissipated. The discharge power was calculated by multi-

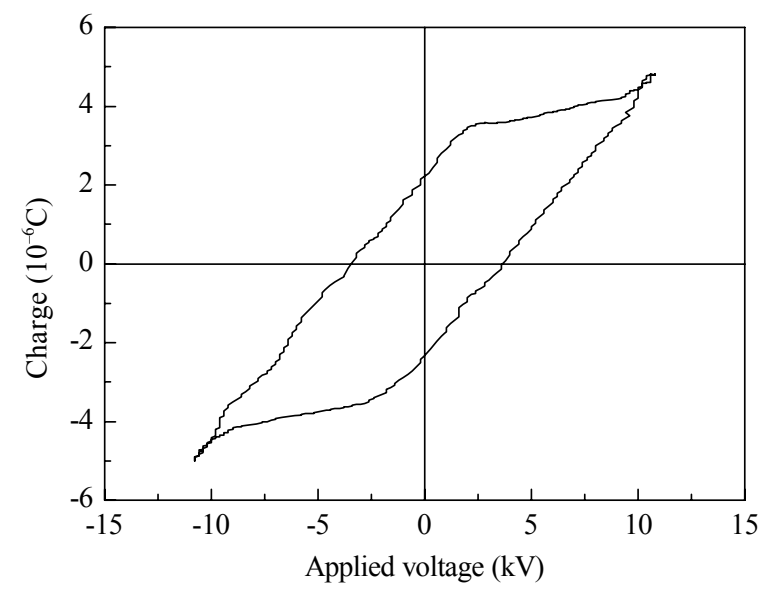

Fig. 3. V-Q Lissajous figure of the DBD reactor at $300 \mathrm{~J} / \mathrm{L}$.

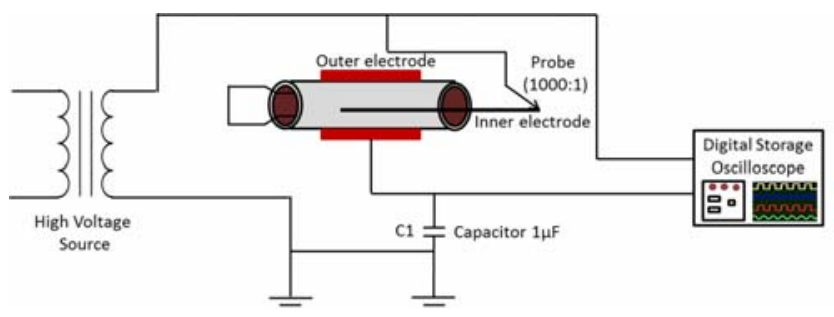

Fig. 2. Electrical circuit of the reactor used. 
plying the area of the V-Q figure with the frequency. The specific input energy (SIE) of the discharge was calculated using SIE $(\mathrm{J} / \mathrm{L})=$ Power $(\mathrm{W}) /$ gas flow rate $(\mathrm{L} / \mathrm{s})$. Increasing the applied voltage increased the power and SIE. For example, at $50 \mathrm{~Hz}$ and $500 \mathrm{ml} / \mathrm{min}$, SIE was increased from 60 $(14 \mathrm{kV})$ to $310 \mathrm{~J} / \mathrm{L}(22.0 \mathrm{kV})$.

\section{Results and discussion}

\subsection{Effect of applied voltage on the destruction of nitrobenzene}

The conversion of $100 \mathrm{ppm}$ of nitrobenzene was followed as a function of the SIE. The conversion increased with increasing SIE. Figure 4(a) shows the activity of different catalytic electrodes during the conversion of $100 \mathrm{ppm}$ of nitrobenzene for applied voltages of 14 to $22.0 \mathrm{kV}$, which corresponded to SIE of 60 and $310 \mathrm{~J} / \mathrm{L}$, respectively. With the SMF electrode, the nitrobenzene conversion reached $67 \%$ at $310 \mathrm{~J} / \mathrm{L} . \mathrm{CoO}_{x} / \mathrm{SMF}$ and $\mathrm{MnO}_{x} / \mathrm{SMF}$ electrodes under the same conditions showed $80 \%$ and $90 \%$ conversion, respectively. The improved performance with $\mathrm{CoO}_{x} / \mathrm{SMF}$ and $\mathrm{MnO}_{x} / \mathrm{SMF}$ electrodes may be due to the formation of active oxygen species on the metal oxide surface by in situ decomposition of ozone. One of the major problems in plasma catalytic techniques is the deposition of polymerized products on the electrode. But in the present study, no carbon deposit was observed in the DBD reactor with any of the catalytic electrodes $\left(\sim 100 \%\right.$ selectivity for $\left.\mathrm{CO}_{x}\right)$. Figure 4(b) shows the selectivity for $\mathrm{CO}_{2}$ of the different catalysts in the destruction of $100 \mathrm{ppm}$ of nitrobenzene. Nitrobenzene was completely oxidised. As compared with SMF and $\mathrm{MnO}_{x} / \mathrm{SMF}$, the $\mathrm{CoO}_{x} / \mathrm{SMF}$ electrode had the highest activity. Even at $100 \mathrm{~J} / \mathrm{L}, \mathrm{MnO}_{x} / \mathrm{SMF}$ gave a conversion of $70 \%$, which reached $90 \%$ at $310 \mathrm{~J} / \mathrm{L}$, but the $\mathrm{CoO}_{x} / \mathrm{SMF}$ electrode showed still better performance.

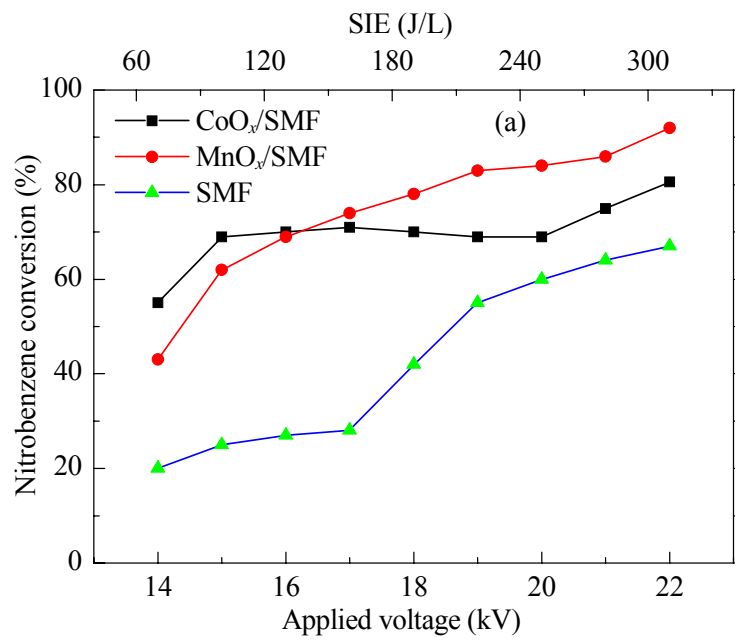

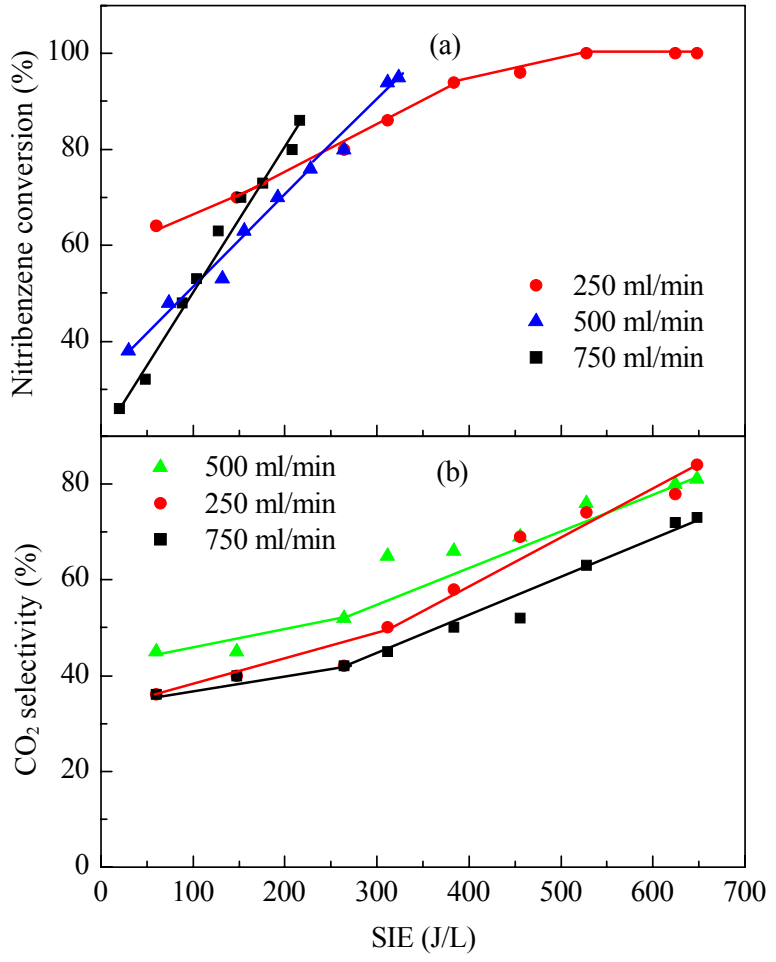

Fig. 5. Influence of SIE and flow rate on nitrobenzene conversion (a) and $\mathrm{CO}_{2}$ selectivity (b) for $500 \mathrm{ppm}$ of nitrobenzene.

\subsection{Influence of residence time on the reactor performance}

The influence of flow rate and concentration at a fixed discharge gap on nitrobenzene decomposition was studied. The flow rates were 250,500 , and $750 \mathrm{ml} / \mathrm{min}$, which corresponded to gas residence times of $3.1,1.5$, and $1.03 \mathrm{~s}$, respectively. The initial concentration was $500 \mathrm{ppm}$. Figure 5(a) shows the conversion of nitrobenzene as a function of SIE. Nitrobenzene conversion increased with increasing SIE and decreasing flow rate. For $3.1 \mathrm{~s}$ residence time, nitro-

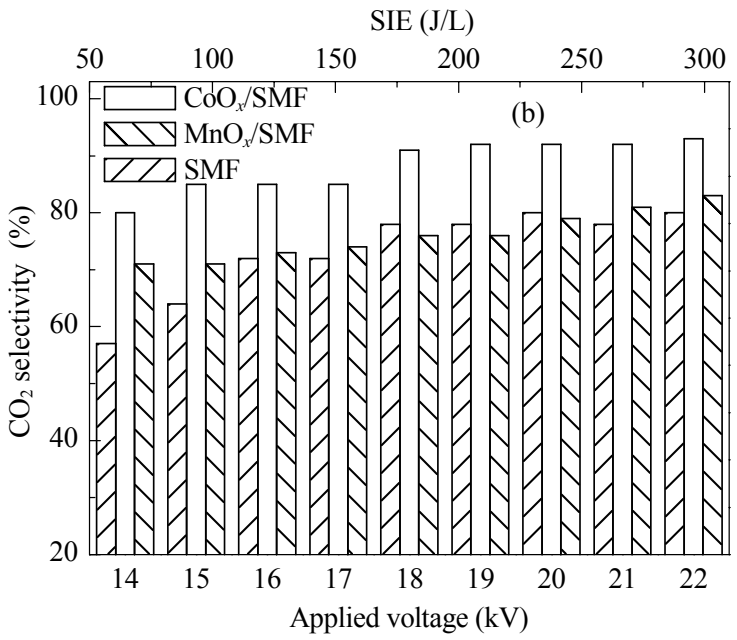

Fig. 4. Influence of SIE on nitrobenzene conversion (a) and $\mathrm{CO}_{2}$ selectivity (b) with different catalytic electrodes. 
benzene conversion reached $100 \%$ at a SIE of $684 \mathrm{~J} / \mathrm{L}$, which decreased to $95 \%$ and $85 \%$ for 1.5 and $1.03 \mathrm{~s}$ that corresponded to the SIE of 324 and $216 \mathrm{~J} / \mathrm{L}$, respectively. Figure 5(b) shows the selectivity for $\mathrm{CO}_{2}$ as a function of SIE. From the Fig. 5(b), a longer residence time of the gas gave a better performance.

The influence of initial concentration was studied. Typical results are presented in Fig. 6(a). The conversion of nitrobenzene at different concentrations as a function of SIE and initial concentration varied between 400 and $800 \mathrm{ppm}$. The conversion of nitrobenzene decreased with increasing inlet concentration of nitrobenzene. The removal efficiency for $400 \mathrm{ppm}$ of nitrobenzene at SIE of $324 \mathrm{~J} / \mathrm{L}$ was $\sim 95 \%$, which decreased to $\sim 85 \%$ for 600 and $800 \mathrm{ppm}$. Figure $6(\mathrm{~b})$ presents the selectivity for $\mathrm{CO}_{2}$ as a function of SIE. For $400 \mathrm{ppm}$ of nitrobenzene, the selectivity for $\mathrm{CO}_{2}$ was $\sim 90 \%$ at a SIE of $324 \mathrm{~J} / \mathrm{L}$, which decreased to $75 \%$ for $800 \mathrm{ppm}$.

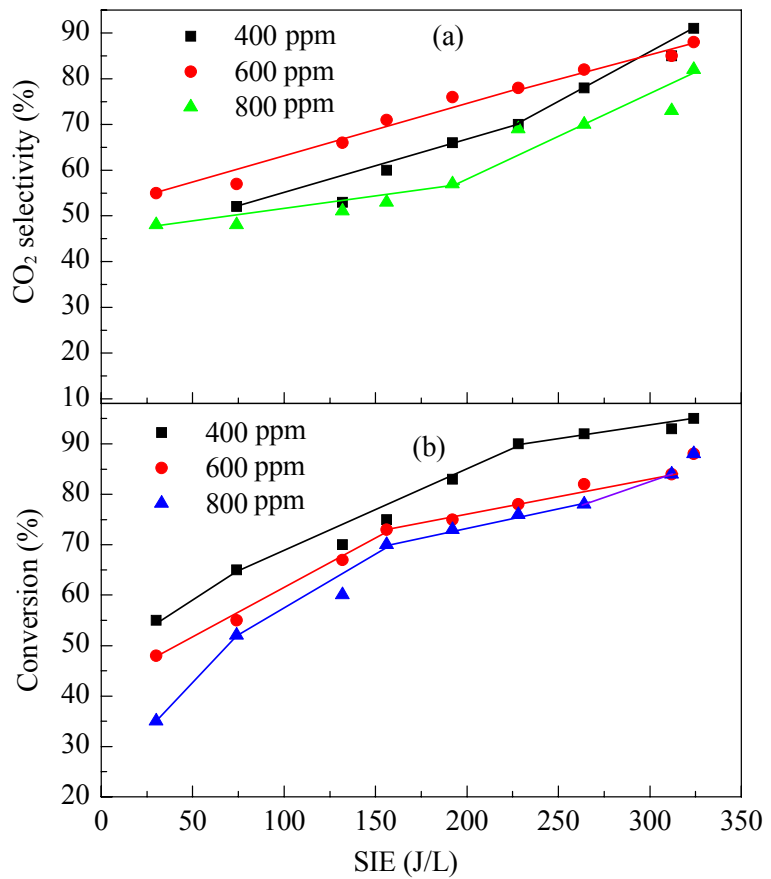

Fig. 6. Influene of SIE and concentration of nitrobenzene on nitrobenzene conversion (a) and $\mathrm{CO}_{2}$ selectivity (b) for different concentrations.

\subsection{Influence of initial concentration of nitrobenzene on the reactor performance}

To understand the influence of the concentration of nitrobenzene on the performance of the reactor, the initial concentration was varied between 100 and $500 \mathrm{ppm}$ at a SIE of $190 \mathrm{~J} / \mathrm{L}$. The results are presented in Fig. 7(a). The conversion decreased with increasing concentration of nitrobenzene from 100 to $500 \mathrm{ppm}$. With the SMF electrode at a SIE of $190 \mathrm{~J} / 1$, for $100 \mathrm{ppm}$ of nitrobenzene, the conversion was $\sim 60 \%$, which decreased to $30 \%$ for $500 \mathrm{ppm}$. A similar trend was observed for the DBD reactor with the $\mathrm{CoO}_{x} / \mathrm{SMF}$ and $\mathrm{MnO}_{x} / \mathrm{SMF}$ electrodes. Of the two catalysts, $\mathrm{CoO}_{x} / \mathrm{SMF}$ showed the better activity.

Figure 7(b) presents the selectivity for $\mathrm{CO}_{x}\left(\mathrm{CO}_{2}+\mathrm{CO}\right)$ as a function of concentration of nitrobenzene, which was varied between 100 and $500 \mathrm{ppm}$. As partially oxygenated products were not detected at the outlet of the reactor, $\mathrm{CO}_{x}$ selectivity also was the carbon balance of the reaction. For $100 \mathrm{ppm}$ of nitrobenzene, with the SMF electrode, there was $\sim 90 \%$ selectivity for $\mathrm{CO}_{x}$, whereas for $500 \mathrm{ppm}$, it was only $60 \%$ and the remaining $40 \%$ was in the form of undesired solid deposits. Interestingly, the selectivity for $\mathrm{CO}_{x}$ was high with the modified SMF electrodes, where for $100 \mathrm{ppm}$, $\sim 100 \%$ selectivity for $\mathrm{CO}_{x}$ was observed. Figure 7 (c) presents the selectivity for $\mathrm{CO}_{2}$, which decreased significantly with increasing nitrobenzene concentration. For $100 \mathrm{ppm}$, the SMF electrode showed $70 \%$ selectivity for $\mathrm{CO}_{2}$, which dropped to $40 \%$ for $500 \mathrm{ppm}$. It is worth pointing out that

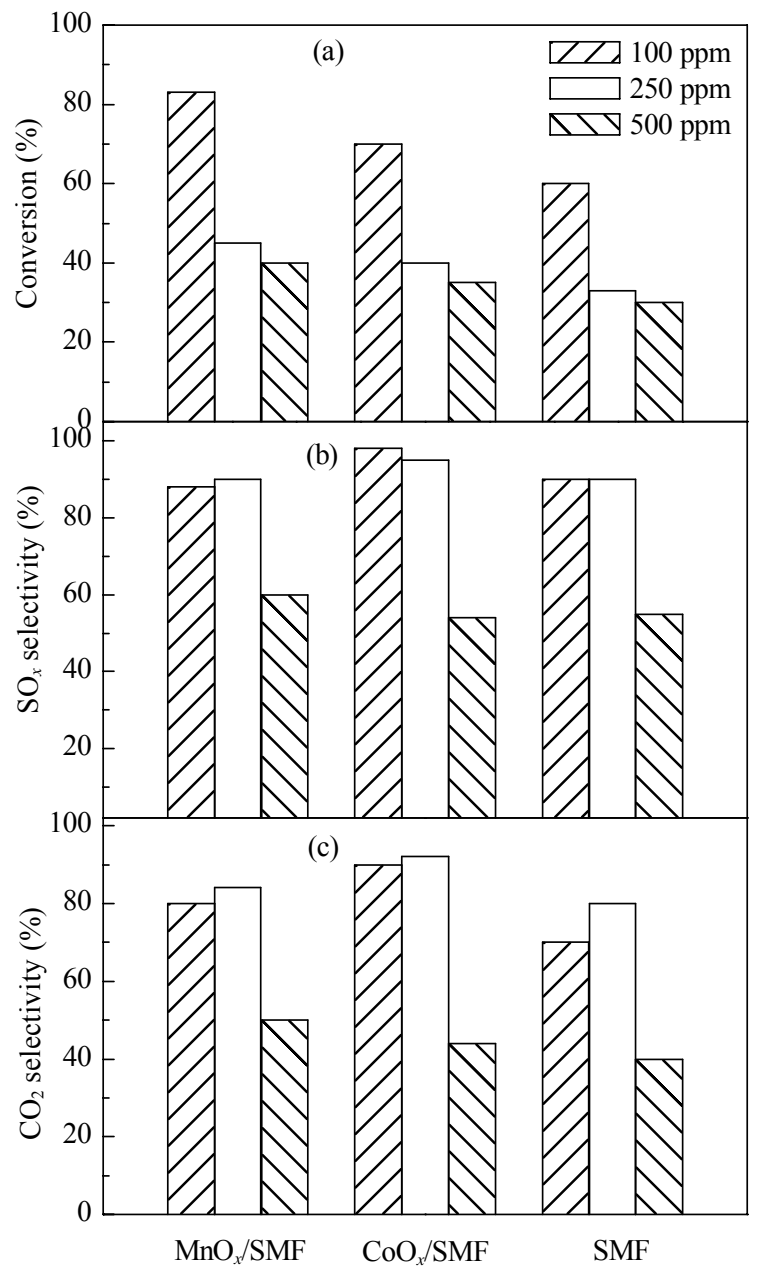

Fig. 7. Influence of the intial concentration of nitrobezene on nitrobenzene conversion (a), $\mathrm{CO}_{2}$ selectivity (b), and $\mathrm{CO}_{x}\left(\mathrm{CO}+\mathrm{O}_{2}\right)$ selectivity (c) at SIE of $190 \mathrm{~J} / \mathrm{L}$. 
the modified SMF electrodes showed a higher selectivity for $\mathrm{CO}_{2}$, especially for the nitrobenzene concentration of 100 ppm.

\subsection{Ozone formation in the DBD reactor}

It is known that NTP produce ozone from air by the ionization of oxygen molecules $[23,24]$. In the catalytic plasma approach, the role of the catalyst is to facilitate in situ decomposition of ozone to produce the highly active atomic oxygen oxidant [19,25-28]. Figure 8 shows the influence of the catalytic electrodes on in situ ozone decomposition. At $100 \mathrm{~J} / \mathrm{L}$, ozone formation was $720 \mathrm{ppm}$ with the SMF, which decreased to 450 and 280 with the $\mathrm{CoO}_{x} / \mathrm{SMF}$ and $\mathrm{MnO}_{x} / \mathrm{SMF}$ electrodes, respectively. The interaction of ozone with the metal oxide catalyst probably increased the formation of reactive atomic oxygen, which resulted in improved performance. $\mathrm{CoO}_{x} / \mathrm{SMF}$ showed a higher activity than $\mathrm{MnO}_{x} / \mathrm{SMF}$. Further studies are in progress to understand the higher activity of $\mathrm{CoO}_{x}$ over $\mathrm{MnO}_{x}$.

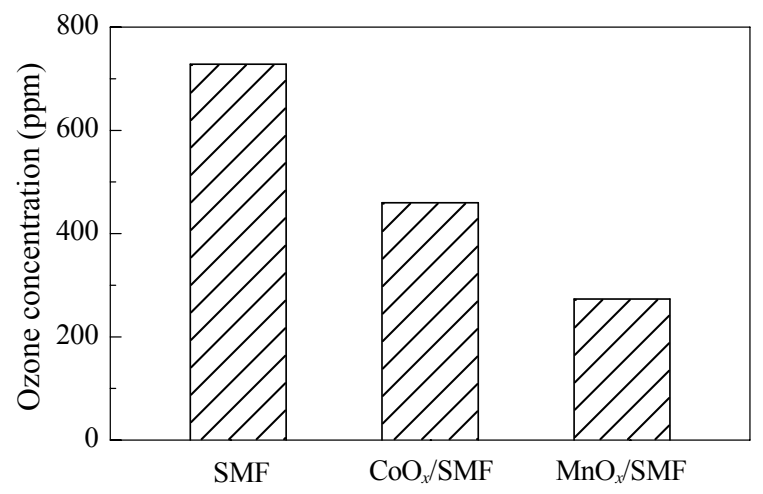

Fig. 8. Activity of the SMF electrodes during ozone decomposition. Applied voltage $=16 \mathrm{kV}$.

\section{Conclusions}

The oxidative decomposition of low concentrations of nitrobenzene was carried out in a catalytic plasma reactor with a modified inner electrode, and the reactor was optimized for a better performance. The modification of the SMF inner electrode with transition metal oxides like $\mathrm{MnO}_{x}$ and $\mathrm{CoO}_{x}$ promoted total oxidation, especially at low concentrations. In the removal of $100 \mathrm{ppm}$ of nitrobenzene, the selectivity to $\mathrm{CO}_{2}$ was $\sim 100 \%$ at $300 \mathrm{~J} / \mathrm{L}$ with the $\mathrm{CoO}_{x} / \mathrm{SMF}$ catalytic electrode, which gave a higher activity than $\mathrm{MnO}_{x} / \mathrm{SMF}$.

\section{Acknowledgements}

The authors thank DST India for financial support under the SERC scheme. CS also thanks Prof. Albert Renken and
Prof. Kiwi-Minsker, EPFL, Swiss for their help.

\section{References}

1 Urashima K, Chang J S. IEEE Trans Ind Appl, 2000, 7: 602

2 Subrahmanyam Ch, Magureanu M, Renken A, Kiwi-Minsker L. Appl Catal B, 2006, 65: 150

3 Holder J W. Toxicol Ind Health, 1999, 15: 445

4 Mcinnes R G. Chem Eng Prog, 1995, 91(11): 35

5 Song Y H, Kim S J, Choi K, Yamamoto T. J Electrostat, 2002, 55: 189

6 Kogelschatz U. Plasma Chem Plasma Process, 2003, 23: 1

7 Holzer F, Roland U, Kopinke F D. Appl Catal B, 2002, 38: 163

8 Oda T. J Electrostat, 2003, 57: 293

9 Penetrante B M, Hsiao M C, Bardsley J N, Merritt B T, Vogtlin G E, Kuthi A, Burkhart C P, Bayless J R. Plasma Sources Sci Technol, 1997, 6: 251

10 Durme J V, Dewulf J, Leys C, Langenhove H V. Appl Catal B, 2008, 78: 324

11 Subrahmanyam Ch, Renken A, Kiwi-Minsker L. Appl Catal B, 2006, 65: 157

12 Karuppiah J, Sivachandiran L, Karvembu R, Subrahmnayam Ch. Chem Eng J, 2010, 165: 194

13 Subrahmanyam Ch, Magureanu M, Renken A, Kiwi-Minsker L. Appl Catal B, 2006, 65: 150

14 Subrahmanyam Ch, Magureanu M, Laub D, Renken A, KiwiMinker L. J Phys Chem C, 2007, 111: 4315

15 Kiyokawa K, Matsuoka H, Itou A, Hasegawa K, Sugiyama K. Surf Coat Technol, 1999, 112: 25

16 Kirkpatrick M J, Finney W C, Locke B R. Catal Today, 2004, 89: 117

17 Czernichowski A. NATO ASI Ser, Ser G, 1993, 34: 371

18 Roland U, Holzer F, Kopinke F D. Appl Catal B, 2005, 58: 217

19 Holzer F, Roland U, Kopinke F D. Appl Catal B, 2005, 58: 227

20 Holzer F, Roland U, Kopinke F D. Appl Catal B, 2002, 38: 163

21 Magureanu M, Mandache N B, Eloy P, Gaigneaux E M, Parvulescu V I. Appl Catal B, 2005, 61: 12

22 Subrahmanyarn C, Renken A, Kiwi-Minsker L. Plasma Chem Plasma Process, 2007, 27: 13

23 Roland U, Holzer F, Kopinke F D. Catal Today, 2002, 73: 315

24 Futamura S, Einaga H, Kabashima H, Hwan L Y. Catal Today, 2004, 89: 89

25 Dhandapani B, Oyama S T. Appl Catal B, 1997, 11: 129

26 Futamura S, Zhang A H, Yamamoto T. J Electrostat, 1997, 42: 51

27 Yamamoto T, Mizuno K, Tamori I, Ogata A, Nifuku M, Michalska M, Prieto G. IEEE Trasn Ind Appl, 1996, 32: 100

$28 \mathrm{Kim} \mathrm{H} \mathrm{H,} \mathrm{Oh} \mathrm{S} \mathrm{M,} \mathrm{Ogata} \mathrm{A,} \mathrm{Futamura} \mathrm{S.} \mathrm{Appl} \mathrm{Catal} \mathrm{B,} \mathrm{2005,}$ 56: 213 